\title{
O estudante, o médico e o professor de medicina perante a morte e o paciente terminal
}

\author{
A. Vianna, H. PICCELli \\ Hospital Universitário de Brasília; Faculdade de Ciências da Saúde da Universidade de Brasília, Brasília, DF.
}

RESUMO - OвJ ETIvo. Determinar o perfil do estudante, do médico e do professor de medicina, em um hospital universitário, diante da morte e de pacientes terminais, e identificar possíveis mudanças de comportamento ao longo e após a formação médica.

Casuística e Método. Inquérito sobre morte e paciente terminal foi realizado entre 81 estudantes da fase pré-clínica e 139 da fase clínica do curso de medicina, 52 médicos e 54 professores da Faculdade de Ciências da Saúde.

Resultados. $O$ interesse pelo assunto foi manifestado por 303 inquiridos (93\%); 179 apresentaram dificuldade para tratar da matéria (55\%). Apenas 136 procuraram informações sobre o tema (41,7\%); 116 tinham dificuldade para encontrá-las $(85,1 \%)$. F ontes de informação leigas for am as mais utilizadas $(61,1 \%)$, em detrimento de fontes especializadas (38,9\%). Apenas 20 médicos (38\%) e 13 professores (24\%) discutiram o assunto com pacientes; 47 alunos da fase pré-clínica discutiram com amigos (58\%) e 40 com familiares (49,4\%); 36 professores debateram com profissionais da área

\section{INTRODUÇÃO}

Facear a morte constitui permanente desafio para o homem desde as mais remotas civilizações. A Medicina, mais do que qualquer outra ciência, coloca diretamente a problemática da morte diante do profissional. O médico responde a esse desafio muitas vezes com ansiedade, medo e até como ameaça à sua própria vida ${ }^{1}$.

Nas duas últimas décadas, a literatura científica tem sido pródiga em publicações sobre as atitudes do médico diante da morte e do paciente terminal. Entretanto, há poucos indícios capazes de definir se tais reações surgem durante o exercício da profissão, em face de situações concretas envolvendo a morte de pacientes, ou se há predisposições trazidas ou desenvolvidas durante a formação médica.

O presente estudo tem como objetivos determi nar algumas características do perfil do estudante, do médico e do professor de medicina, ligados a um de saúde $(66,6 \%)$.

Pensam, eventualmente, na própria morte 263 entrevistados (80,7\%) e, constantemente, 38 (11,6\%); 157 sentem medo quando o fazem (52,2\%). Nunca pensaram na própria morte 11 alunos da fase préclínica $(13,8 \%)$, dez da fase clínica $(7,2 \%)$ e quatro médicos $(7,4 \%)$.

Antes de iniciar o curso médico, 136 inquiridos tiveram algum contato com cadáver $(41,8 \%)$. O interesse pelo assunto morte não se alterou, ou até aumentou, após contato com o cadáver, para 321 (98,5\%), ou mesmo após as primeiras necropsias, para $236(96,3 \%)$. Na fase clínica do curso, 111 alunos (79,9\%) tiveram contato com pacientes terminais.

ConClusões. Os autores suger em que a educação formal sobre o assunto nas escolas de medicina, desde o início do curso, bem como a permanente atenção dispensada ao tema por parte dos profissionais, poderia modificar o comportamento do estudante e do médico, tornando-os mais aptos a lidar com a morte e com o paciente terminal.

UNITERmos: Paciente terminal. Morte. Educação médica.

hospital universitário, diante da morte e de pacientes terminais, e identificar possíveis mudanças de comportamento ao longo e após a formação médica.

\section{MÉ TODO}

No período de agosto a novembro de 1993, questi onário referente aos temas morte e paciente terminal foi aplicado a estudantes do curso de medicina, médicos residentes e assistentes, e professores do H ospital U niversitário de Brasília e da F aculdade de Ciências da Saúde da Universidade de Brasília. O inquérito continha questões objetivas, em número de 46, para os estudantes da fase préclínica do curso (primeiro ao quarto semestre), 79 para os estudantes da fase clínica (quinto ao décimo-segundo semestre), 79 para os médicos e 84 para os professores. Algumas questões ofereciam mais de uma opção como resposta. Não foi solicitada a identificação nominal do respondente, que 
assinalou apenas dados demográficos, como sexo, idade, naturalidade, o semestre que cursava (para estudantes), o ano de resi dência médica, especial idade e tempo de profissão (para médi cos) e disciplina que ministrava (para professores). Os questionários aplicados aos estudantes da fase clínica e aos médicos continham questões que implicavam em al guma experiência clínica. Ao questionário dos professores foram acrescentadas questões referentes à experiência docente.

E studo-pil oto foi realizado, solicitando-se a indivíduos escol hidos al eatoriamente, de cada população a ser estudada, que fizessem críticas e sugestões sobre a clareza, facilidade de preenchimento e opções de respostas oferecidas no questionário, após o que as devidas correções foram efetuadas.

Devido ao grande volume de informações resultantes, a presente publicação inclui apenas parte das respostas obtidas no inquérito.

A análise estatística foi realizada utilizando-se o método do $\chi^{2}$, sendo $p<0,05$ consi derado significante.

\section{RESULTADOS}

Foram distribuídos 455 questionários e respondidos 326 (71,6\% de índice de devolução), por 81 estudantes da fase pré-clínica (85,3\%), 139 da fase clínica (64,6\%), 52 médi cos (residentes e assistentes) $(67,5 \%)$ e 54 professores $(79,4 \%)$.

Dos entrevistados, 195 eram do sexo masculino $(60,3 \%)$ e 131 do feminino (39,7\%). A idade variou de 16 a 66 anos (Mdn 27,3 anos): 16 a 27 anos entre alunos da fase pré-clínica (Mdn 19 anos), 19 a 41 anos entre os da fase clínica (Mdn 21 anos), 23 a 57 anos entre médicos (Mdn 32 anos) e 29 a 66 anos entre professores ( $M d n$ 47,5 anos).

N oventa e oi to estudantes do curso de graduação eram naturais do Distrito Federal (44,5\%), 23 do Rio de J aneiro (10,4\%), 16 de Minas Gerais (7,3\%), 15 de São Paulo (6,8\%), 13 de Goiás (5,9\%), seis do Exterior (2,7\%), al ém de 39 de 12 outros Estados da Federação (17,7\%). Dez alunos não informaram sua naturalidade (4,6\%). E ntre os médicos e professores, 18 eram de Minas Gerais (16,9\%), 14 do Rio de J aneiro (13,2\%), 11 da Bahia (10,3\%), sete do Distrito Federal $(6,6 \%)$, seis de Goiás $(5,6 \%)$, quatro do Exterior (3,7\%), além de 39 de 12 outros Estados (36,7\%). Sete indivíduos desse grupo não informaram sua naturalidade $(6,6 \%)$.

A distribuição dos estudantes de medicina que responderam ao inquérito, nas fases pré-clínica e clínica do curso, de acordo com o semestre letivo que cursavam, é mostrada na tabela 1.

Entre os médicos residentes, cinco cursavam o primeiro ano de residência (20,8\%), 14 o segundo

\begin{tabular}{|lccc|}
\hline \multicolumn{3}{|l|}{$\begin{array}{l}\text { Tabela 1 - Distribuição dos alunos do curso de Medicina } \\
\text { por semestre }\end{array}$} & \multicolumn{3}{l}{} \\
\hline Fase do curso & Semestre & N o de alunos & $\%$ \\
Fase pré-clínica & 1 & 25 & 11,3 \\
& 2 & 20 & 9,0 \\
& 3 & 20 & 9,0 \\
Fase clínica & 4 & 16 & 7,2 \\
& 5 & 23 & 10,4 \\
& 6 & 25 & 11,3 \\
& 7 & 21 & 9,5 \\
& 8 & 15 & 6,8 \\
& 9 & 14 & 6,3 \\
& 10 & 28 & 12,7 \\
Total & 11 & 7 & 3,1 \\
& 12 & 6 & 2,7 \\
& & 220 & 100 \\
\hline
\end{tabular}

Tabela 2 - Distribuição dos médicos assistentes e professores que responderam ao inquérito por departamentos da Faculdade de Ciências da Saúde da Universidade de Brasília
Departamentos

Morfologia (área básica)

Clínica Médica

Clínica Cirúrgica

Ginecologia e Obstetrícia

Pediatria

Saúde coletiva

Total

Médicos
residentes (\%)

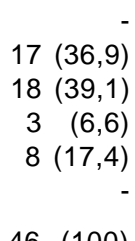

$46(100)$
Professores (\%)

$10(18,9)$

$19(35,8)$

$9(16,9)$

$3(5,7)$

$9(16,9)$

$3(5,7)$

$53(100)$
(58,3\%) e cinco o terceiro ano (20,8\%). A experiência profissional dos médicos assistentes foi, em média, de 14,5 anos (sd $\pm 8,3$ anos), e dos professores, de 21,8 anos (sd $\pm 8,8$ anos).

A distribuição dos médicos assistentes e professores que responderam ao inquérito, por departamentos da F acul dade de Ciências da Saúde, é mostrada na tabela 2.

0 interesse pelo assunto morte foi manifestado por 303 respondentes (93\%), dos quais 179 (55,5\%) experimentaram algum grau de dificuldade para tratar do tema. Essa dificuldade é relatada por 57 alunos da fase pré-clínica (70,4\%), 86 da fase clínica $(61,8 \%), 26$ médi cos $(50,9 \%), 25$ professores $(46,3 \%)$, diferença estatisticamente não significante $(p>0,05)$. Sete médicos $(13,5 \%)$ e sete professores (13\%) permaneceram com muita dificuldade para tratar do assunto. Evitaramoassunto mortequatroal unos da fase pré-clínica $(4,9 \%)$, três da fase clínica $(2,2 \%)$, um médico (1,9\%) e três professores $(5,6 \%)$.

Cento e trinta e seis inquiridos têm procurado informações sobre o assunto $(41,7 \%)$, dos quais 116 têm dificuldade para encontrá-las $(85,1 \%)$, índice que chega a $96,7 \%$ entre os professores. Informações sobre o assunto têm sido obtidas principal- 
Tabela 3 - Grupos com os quais foram debatidos os temas morte e paciente terminal pelos respondentes. A indicação de mais de uma opção como resposta foi facultada aos entravistados

\begin{tabular}{|c|c|c|c|c|c|c|c|c|c|c|}
\hline \multirow{2}{*}{$\begin{array}{l}\text { Grupos de debates } \\
\text { Amigos }\end{array}$} & \multicolumn{2}{|c|}{$\begin{array}{l}\text { Alunos da fase } \\
\text { pré-clínica }(n=81)\end{array}$} & \multicolumn{2}{|c|}{$\begin{array}{l}\text { Alunos da fase } \\
\text { clínica }(n=139)\end{array}$} & \multicolumn{2}{|c|}{$\begin{array}{l}\text { Médicos residentes } \\
\text { e assistentes }(n=52)\end{array}$} & \multicolumn{2}{|c|}{ Professores $(n=54)$} & \multicolumn{2}{|c|}{ Total $(n=326)$} \\
\hline & 47 & $(30,7 \%)$ & 99 & $(25,2 \%)$ & 39 & $(24,0 \%)$ & 20 & $(17,8 \%)$ & 205 & $(25 \%)$ \\
\hline Familiares & 40 & $(26,1 \%)$ & 71 & $(18,1 \%)$ & 33 & $(20,3 \%)$ & 1 & $(15,1 \%)$ & 161 & $(19,6 \%)$ \\
\hline $\begin{array}{l}\text { Professores } \\
\text { Profissionais da }\end{array}$ & 20 & $(13,0 \%)$ & 91 & $(23,2 \%)$ & 20 & $(12,3 \%)$ & 15 & $(13,3 \%)$ & 146 & $(17,8 \%)$ \\
\hline área de saúde & 18 & $(11,7 \%)$ & 67 & $(17,0 \%)$ & 31 & $(19,1 \%)$ & 36 & $(32,1 \%)$ & 152 & $(18,5 \%)$ \\
\hline Religiosos & 27 & $(17,6 \%)$ & 46 & $(11,7 \%)$ & 19 & $(11,7 \%)$ & 11 & $(9,8 \%)$ & 103 & $(12,6 \%)$ \\
\hline Pacientes & 1 & $(0,6 \%)$ & 18 & $(4,5 \%)$ & 20 & $(12,3 \%)$ & 13 & $(11,6 \%)$ & 52 & $(6,3 \%)$ \\
\hline
\end{tabular}

mente de fontes leigas $(61,1 \%)$, como televisão $(13,7 \%)$, cultos religiosos $(12,7 \%)$, revistas leigas $(11,6 \%)$, literatura em geral $(10,5 \%)$, jornais $(8,7 \%)$ e outras fontes (3,9\%). As fontes especializadas têm sido menos utilizadas $(38,9 \%)(p<0,001)$, tais como debates e seminários sobre morte (14,3\%), livros (13,7\%) e periódicos especial izados (10,5\%). As informações obtidas foram consideradas insatisfatórias, ou pouco satisfatórias, por 83 indivíduos (61,1\%), índice que chega a 78,1\% entre médicos.

Cento e cinqüenta inquiridos participaram, uma ou duas vezes apenas, de debates sobre morte (46\%), e 130 deles já o fizeram várias vezes (40\%). Nunca participaram de debates 46 entrevistados (14\%): 24 al unos da fase pré-clínica $(29,6 \%)$, seteda fase clínica $(5,1 \%)$, cinco médi cos $(9,3 \%)$ e dez professores $(18,5 \%) \quad(p<0,001)$. Dentre os 280 que já participaram al guma vez de debates sobre o assunto, 212 foram influenciados de forma positiva por eles $(75,7 \%)$.

Os diversos grupos com os quais foram debatidos os temas morte e paciente terminal são indicados na tabela 3.

Cento e noventa e oito respondentes $(60,7 \%)$ já vivenciaram a morte de familiar próximo; 135 , de um amigo (41,4\%); 90 , de um desconhecido $(27,6 \%)$; 84 , de familiar distante $(25,7 \%)$. Com relação à morte de pacientes, esta vivência ocorreu com três alunos da fase pré-clínica (3,7\%), 67 da fase clínica (48,2\%), 34 médicos (65,3\%) e 25 professores $(46,2 \%)$. Quando o paciente estava sob os cuidados ou responsabilidade direta do entrevistado, essa vivência ocorreu com 21 alunos da fase clínica (15,1\%), 49 médicos (94\%) e 40 professores (74\%). Vinte e sete alunos da fase pré-clínica (33,3\%), 12 da fase clínica $(8,6 \%)$ e um professor $(1,8 \%)$ nunca vivenciaram a morte de outrem. Todos os 52 médicos já vivenciaram a morte de outrem. Dentre os 24 entrevistados que nunca vivenciaram a morte de outrem, 15 têm receio de que isso venha a ocorrer $(61,2 \%)$.

Dentre os 302 que tiveram vivências prévias relacionadas à morte, estas ocorreram poucas ve- zes (uma a três vezes) com 47 alunos da fase préclínica $(87,1 \%)$ e 83 da fase clínica $(65,6 \%)$. Ocorreram várias vezes (mais de três vezes) com 45 médi$\cos (86,5 \%)$ e 41 professores $(76,9 \%)(p<0,001)$.

Ainda dentre aqueles que tiveram vivências prévias, para 198 tais experiências relacionaram-se à morte após doença crônica de longa duração $(65,5 \%)$; para 171, morte após alguns dias ou semanas de doença (56,6\%); e para 193, morte súbita (63\%) $(p>0,05)$. Para $152(50,3 \%)$, tais experiências influenciaram de forma positiva seu modo de encarar o assunto; para 29, el as influenciaram negativamente $(9,6 \%)$; e para 29 , elas não tiveram qualquer influência $(9,6 \%)$. Oitenta entrevistados não souberam avaliar $(26,4 \%)$.

Quando perguntados sobre sua possível reação, ao serem col ocados diante de indi víduo portador de doença terminal, 155 entrevistados (47,4\%) responderam que teriam receio em tratar do assunto, 32 deles (9,9\%) evitariam abordar o assunto e 139 $(42,7 \%)$ não teriam receio.

Pensam, eventualmente, na própria morte 263 respondentes $(80,7 \%)$ e, constantemente, 38 deles $(11,6 \%)$. Nunca pensaram na própria morte 11 alunos na fase pré-clínica (13,8\%), dez da fase clínica (7,2\%) equatro médicos (7,4\%). Todos os professores já cogitaram de sua própria morte $(p<0,05)$. Dos 301 entrevistados que pensam na própria morte, 157 sentem medo quando o fazem (52,3\%).

Quando perguntados se já haviam, de alguma forma, vivenciado a possibilidade concreta de sua própria morte, 227 responderam que não $(69,6 \%), 75$ que sim (23\%), após acidente, e 24, após doença grave (7,4\%). Dentre os 99 que já vivenciaram a possibilidade concreta da própria morte, 59 foram influenciados positivamente pela experiência (59,8\%), para 12 a influência foi negativa $(11,6 \%)$ e 28 não se deixaram influenciar $(28,6 \%)(p<0,01)$.

Antes de iniciar o curso médico, 136 indivíduos tiveram al gum ti po de contato com cadáver $(41,8 \%)$, 147 não o tiveram por falta de oportunidade $(45,1 \%)$ 
e 43, por falta de interesse (13,1\%). Dentre os que tiveram contato prévio, tal experiência refletiu-se de forma positiva em 43 deles (31,3\%), não influenciou 55 (40,4\%), sendo negativa em 12 (9\%). Vinte e seis não souberam avaliar (19,3\%).

Nos primeiros semestres do curso de medicina, após contato com o cadáver na disciplina de Anatomia, o interesse pelo assunto morte não se alterou para 253 inquiridos (77,7\%). Tal interesse aumentou entre 27 al unos da fase pré-clínica (2,9\%), entre 29 da fase clínica (21,2\%), entre oi to médicos (15,1\%) e entre quatro professores (7,4\%). O interesse diminuiu entre cinco entrevistados $(1,5 \%)(p<0,01)$.

A pós assistirem às primeiras necropsias, na disciplina de Patol ogia, o interesse pelo assunto morte não se alterou para 170 respondentes (69,5\%). O interesse aumentou para 49 al unos da fase clínica (35,6\%), para nove médicos (17\%) e para oito professores (15,1\%), e diminuiu para 12 entrevistados $(4,7 \%)(p<0,001)$.

A partir da fase clínica do curso de medicina, o contato com o paciente terminal ocorreu com 111 alunos (79,9\%), com todos os médicos e com 50 professores $(92,6 \%)(p<0,001)$. Tal contato influenciou de maneira positiva 142 respondentes $(66,8 \%)$, negativamente 12 deles $(5,4 \%)$ e não influenciou 59 deles $(27,7 \%)$.

Gostaram de responder ao presente inquérito 267 indivíduos (81,9\%). O questionário despertou atenção para o assunto morte, de forma positiva, em 247 inquiridos (75,6\%), de forma negativa em 27 deles (8,3\%) e em 52 não despertou atenção (15,9\%). Sentiram-se motivados a buscar maiores informações sobre morte, ou discutir o assunto, 242 indivíduos (74,2\%). Seis não gostaram de responder ao questionário $(1,8 \%)$ e 53 permaneceram indiferentes a el e (16,3\%), tendo 16 al egado dificul dades inerentes ao assunto (4,9\%), 14 pela extensão do questionário (4,3\%), para oito o assunto morte não agrada $(2,4 \%)$ e, para um entrevistado, o questionário foi mal formulado (0,3\%). Vinte alegaram outras razões $(6,1 \%)$.

\section{DISCUSSÃO}

O homem de hoje, por razões históricas e culturais, encara a morte como um problema ${ }^{2-4}$. A despeito da enorme projeção alcançada pelo assunto em anos recentes, os sentimentos e atitudes dos estudantes de medicina e dos médicos com rel ação à morte e ao morrer são pouco conheci dos. Compreendê-los melhor poderia resultar não apenas na resolução de determinadas dificuldades inerentes ao tema, como aprimorar a relação médico-paciente terminal. O presente inquérito, além de procurar estabelecer um perfil dos grupos estudados na sua relação com a morte, buscou identificar possíveis dificuldades manifestadas por estudantes, comparando-as com aquelas apresentadas por médicos (resi dentes eassistentes) e professores de medicina.

Ao mesmo tempo que a grande maioria manifestou interesse pelo assunto morte, relatou também dificuldade para tratar do tema. Essa dificuldade foi maior entre os estudantes, mormente entre aqueles da fase pré-clínica do curso de medicina, quando comparados aos médicos e professores. Kalish e Reynolds ${ }^{5}$ estimam que $30 \%$ a $60 \%$ dos médicos aprendem a lidar com pacientes terminais durante a residência médica. A experiência clínica expõe o profissional da ár ea de saúde ao contato com a morte e, possivelmente, diminui a dificuldade de se tratar do assunto, embora, em muitos casos, não a resolva compl etamente ${ }^{6}$. O presente inquérito evidenciou que número considerável de médicos e professores permanece com muita dificuldade para tratar do assunto, chegando mesmo a evitá-lo.

E m contraste com o interesse demonstrado, a maioria dos entrevistados não procura informações sobre o assunto e, quando o faz, rel ata dificuldade para encontrá-las. Além disso, as informações obti das são consideradas insatisfatórias, provavel mente em função das fontes consultadas, l eigas em sua maioria. Aquilo que poderia parecer paradoxal, isto é, interessar-se pelo assunto e não buscar informações sobre ele, pode ser explicado pelo fato de que pensar a morte, considerá-la em profundidade, é algo doloroso para o homem e traz à tona lembranças de perdas antigas, a dor do luto, o sentimento de finitude e o medo de um futuro completamente desconhecido e incerto ${ }^{7}$.

A participação em debates, conversas ou seminários sobre morte e paciente terminal foi relatada pel a maioria, especial mente a partir da fase clínica do curso de medicina, quando se torna mais freqüente o contato com pacientes terminais. Okin ${ }^{8}$ relata que tal experiência é a principal fonte de aquisição de informações sobre como lidar com tais pacientes. O presente estudo mostrou que número expressivo de alunos da fase pré-clínica e, mais surpreendentemente, de professores, nunca participou de debates ou seminários sobre morte. A ausência de contato com pacientes terminais poderia justificar o desinteresse pelo assunto entre estudantes dessa fase do curso e professores de áreas básicas da medicina.

Entre os al unos, conversas ou debates com amigos e familiares constituíram as formas mais freqüentes de abordar o tema morte, o que sugere a busca de um grupo de identificação, com vivências, atitudes e faixa etária similares. Tal busca é des- 
crita por Barton ${ }^{9}$, que recomenda discussões entre pequenos grupos de estudantes na mesma fase do curso, permitindo que os participantes exponham seus medos e dúvidas, comuns ao grupo, sem qualquer constrangimento. É de se notar que três quartos dos alunos da fase pré-clínica não discutiram o assunto com seus professores, possivelmente por falta de motivação ou de preparo dos docentes ligados às áreas básicas do curso. A discussão, por parte dos professores, preferencialmente com profissionais da área desaúde, podesugerir um enfoquemais técnico do tema, sem que se possa afastar, também, a busca de um grupo de identificação.

O presente inquérito revel ou que médicos e professores, com freqüência, já vivenciaram a morte de pacientes terminais; entretanto, a maioria deles relatou que nunca discutiu o assunto com tais pacientes, e que teria grande dificuldade para tratar do tema com um indivíduo portador de doença terminal. Klafke ${ }^{1}$ sugere que essa dificuldade seja decorrente da falta de preparo desses profissionais, além do comportamento apresentado pelos pacientes durante a evol ução de uma doença ter minal. Howels et al. ${ }^{10}$ relatam que o contato com pacientes terminais pode diminuir o medo de interagir com tais pacientes, porém persiste a dificuldade para se chegar a uma situação ideal, em que o médico não se deixa envolver pelo paciente, a ponto de já não conseguir atuar como profissional, nem se afasta, não deixando de tratá-lo como pessoa doente. Outros autores sugerem que a educação formal sobre morte e o morrer pode diminuir a dificuldade de tratar do assunto com pacientes terminais ${ }^{9,11-14}$, porém, no Brasil, poucas escolas de medicina oferecem tal disciplina em seu currículo ${ }^{7}$. Observou-se, no presente inquérito, que o contato com pacientes terminais intensificou-se com o aumento da experiência clínica e que teve influência positiva na maioria das vezes. O preparo mais adequado para a experi ência com o paciente terminal poderia influenciar positivamente na maneira de encarar o assunto e mel horar o rel acionamento médico-paciente terminal.

Dentre aqueles que nunca vivenciaram a morte de outrem, na sua maior parte alunos da fase préclínica do curso, percentagem elevada tem medo que isso venha a ocorrer. Howells et al. ${ }^{10}$ relatam, no tocante ao medo da morte, diferenças entre alunos que já possuem experiência clínica e aqueles que ainda não a possuem. Porém, mesmo entre os clinicamente experientes, o medo da morte de outrem remete ao medo da própria morte ${ }^{7}$, sem que se possa desprezar as marcas culturais da negação da morte que caracterizam o homem ocidental deste século.
Segundo Sontag ${ }^{15}$, "a boa morte é a repentina, e a melhor de todas é a que ocorre quando estamos inconscientes ou adormecidos". Ariès ${ }^{2}$ descreve o conceito de "boa morte" como sendo aquela que ocorre de modo rápido, asséptico e indolor. O presente inquérito revelou que, para dois terços dos inqui ridos que já vivenciaram a morte de outrem, essa experiência relacionava-se a período mais ou menos prolongado de doença antecedendo à morte. Mesmo assim, para a maioria destes, essas vivências influenciaram positivamente sua maneira de pensar a morte.

A maioria dos entrevistados apenas eventualmente pensa na própria morte, o que pode ser interpretado como uma forma de negação, já que a maioria dos que pensam na própria morte sente medo quando o faz. Kovács ${ }^{16}$ relata que se o medo da morte estivesse constantemente presente, não se conseguiria realizar nada, e quea grande dádiva da negação é permitir que se viva num mundo de fantasia, onde, aparentemente, existe a ilusão da imortalidade. $O$ presente estudo mostrou que os estudantes da fase pré-clínica pensam menos na própria morte que os da fase clínica, médicos e professores. A diferença de idade poderia explicar tal reação ${ }^{17}$, porém ela é mínima entre os alunos das fases pré-clínica e clínica, sugerindo que outros fatores, como o contato com os pacientes e com a doença, estejam envolvidos.

No presente inquérito, observou-se que aproximadamente um terço dos respondentes já vivenciou, após acidente ou doença grave, a possibilidade real ou imaginária da própria morte. Apesar de sentimentos como medo, fatalismo, vontade de viver e perda da onipotência estarem envolvidos ${ }^{18}$, para a maioria deles tal experiência refletiu-se positivamente em sua manei ra de encarar o assunto. O medo da morte é universal, e diversas escalas para avaliá-l o têm sido utilizadas numa variedade de profi ssões, porém existem poucos dados relacionando o medo à preferênci a ocu pacional ${ }^{19,20}$. L oneto e Templer ${ }^{21}$ encontraram pouca rel ação entre medo da morte e escolha da profissão, sem afastar, no entanto, a possibilidade de que a ocupação profissional possa ser, em parte, influenciada pela ansiedade e medo da morte. O contato com cadáver, por meio de visitas de indi víduos leigos a institutos de anatomia e medicina legal, pode ser considerado como uma forma de avaliar esse medo. Zaidhaft ${ }^{7}$ relata a angústia diante da experiênci a com o cadáver antes de ingressar no curso médico eas dúvidas decorrentes quanto à escolha da profissão. No presente estudo, observou-se que, mesmo antes de iniciar o curso médico, percentagem expressiva dos inqui ridos teve al gum ti po de contato com cadáver. 
Isso pode refletir uma característica inerente ao grupo que irá ingressar no curso médi co, porém não há dados que permitam a comparação com outros grupos da população. No presente inquérito, tal experiência não teve qualquer repercussão para a maior parte dos entrevistados.

Kovács ${ }^{16}$ ressalta que, durante a disciplina de Anatomia, no início do curso médico, a doença e a morte são descaracterizadas, e os futuros médicos entram em contato com a morte desper sonal izada, devendo reprimir qualquer sensação de repulsa, nojo ou desespero. Zaidhaft ${ }^{7}$ relata que durante as necropsias, apesar de os estudantes já terem al gum contato com a ideol ogia e cultura médicas, o impacto é mais intenso do que aquele ocasionado pelo cadáver na Anatomia. Entretanto, o presente inquérito revel ou que as experiências na Anatomia e com as necropsias não modi fi car am o inter esse pelo assunto morte para a maioria, chegando mesmo a aumentá-Io, e que apenas uma percentagem muito pequena teve seu interesse diminuído.

O simples fato de responder ao questionário despertou a atenção da maioria dos respondentes, motivando-os a buscar maiores informações sobre o assunto. O problema existencial do homem diante da mortee do morrer não será resol vi do facil mente, porém a educação formal a respeito do assunto nas escolas de medicina, desde o início do curso de graduação, bem como a permanente atenção dispensada ao tema por parte dos profissionais, poderia modificar o comportamento do estudante e do médi co, tornando-os mais aptos a lidar com a morte e com o paciente terminal.

Obs.: Os questionários aplicados no presente estudo estão à disposição dos interessados, desde que solicitados ao Dr. André Vianna - SQN 206 Bloco F - apto. 202, CEP 70844-060, Brasília, DF.

\section{SUMMARY}

\section{The student, the medical doctor and the teacher of medicine facing death and terminal patients}

OBJ ECTIVE. The aim of this investigation was to study the feelings and attitudes of medical students, medical doctors and teachers of medicine facing death and terminal patients.

Method. An inquiry about death and terminal patient was applied to 81 pre-clinical students, 139 clinical students, 52 medical doctors and 54 teachers of the F aculty of $\mathrm{H}$ ealth Sciences.

RESULTS. 303 responders showed interest in this subject (93\%); 179 had problems in dealing with it (55\%). Only 136 searched for information (41.7\%) and 116 have dificulty in finding it (85.1\%). Nonespecialized sources of information were the most used ones (61.1\%). Twenty medical doctors (38\%) and 13 teachers (24\%) discussed the subject more often with patients, 47 pre-clinical students (58\%) did it with friends and 40 with relatives (49.4\%); 36 teachers did it with health professionals (66.6\%). 263 responders rarely think about their own death (80.7\%), and 38 do it constantly (11.6\%); 157 are afraid of thinking about their own death (52.2\%). Eleven pre-clinical students (13.8\%), ten clinical students (7.2\%) and 4 medical doctors (7.4\%) never thought of their own death. B efore entering medical school, 136 responders had some kind of contact with corpses (41.8\%). The interest about death did not change, after dealing with corpses in anatomy classes, to 321 responders (98.5\%), the same hapening with 236 individuals (96.3\%) after necroscopy. During the clinical year 111 students (79.9\%) worked with terminal patients.

Conclusions. The authors suggest that formal education about death and terminal patient in medical schools, starting early in the medical course, as well as permanent attention to the theme by professionals, could modify the attitudes of students and medical doctors toward a better way in dealing with this subject. [Rev Ass Med Brasil 1998; 44(1): 21-7.]

KEY WORDS: Terminal patient. Death. Medical education.

\section{REFERÊ NCIAS BIBLIOGRÁFICAS}

1. Klafke TE. O médico lidando com a morte: aspectos da relação médico-paciente terminal em cancerologia. In Cassorla RMS (ed): Da morte: estudos brasileiros. Campinas, Papirus, 1991; 25-49.

2. Ariés P. História da morte no Ocidente: da Idade Média a nossos dias. Rio de J aneiro, Francisco Alves, 1977.

3. Bessa HA. A morte e o morrer. In D'Assunpção EA, D'Assunpção GH, Bessa HA (ed): Morte e suicídio: uma abordagem multidisciplinar. Petrópolis, Vozes, 1984; 13-25.

4. D'Assunpção EA. Aspectos culturais e psicológicos da morte. In D'Assunpção EA, D'Assunpção GH, Bessa HA (ed): Morte e suicídio: uma abordagem multidisciplinar. Petrópolis, Vozes, 1984; 29-47.

5. Kalish R, Reynolds D. Death and ethnicity: a psycho-cultural study. Los Angeles: University of Southern California Press, 1976.

6. Stedeford A. Encarando a morte. Porto Alegre, Artes Médicas, 1986.

7. Zaidhaft S. Morte e formação médica. Rio de J aneiro, Francisco Alves, 1990.

8. Okin D. What to tell cancer patients: a study of medical attitudes. J AMA 1961; 175: 1.120-5.

9. Barton D. The need of including instruction on death and dying in the medical curriculum. J Med Educ 1992; 47: 169-75.

10. Howells K, Gould M, Flelds D. Fear of death and dying in medical students: effects of clinical experience. Med Educ 
1986; 20: 502-6.

11. Thorson J A. Variations in death anxiety related to college students' sex, major field of study and certain personality traits. Psycol Rep 1977; 40: 857-8.

12. Smith LD, McSweeney M, Katz M. Characteristics of death education curricula in american medical schools. J Med Educ 1980; 55(1): 844-50.

13. Field D. Formal instruction in United Kingdom medical schools about death and dying. Med Educ 1984; 18: 429-34.

14. Rappaport W, Witzke D. Education about death and dying during the clinical years of medical school. Surg 1993; 113(2): 163-5.

15. Sontag S. A doença como metáfora. Rio de J aneiro, Graal, 1984

16. Kovács MJ . Pensando a morte e a formação de profissionais de saúde. In Cassorla RMS (ed): Da morte: estudos brasileiros. Campinas, Papirus, 1991; 79-103.

17. Thorson J A, Powell FC. Medical students' attitudes towards ageing and death: a cross-sequential study. Med Educ 1991; 25: 32-7.

18. Owens J, Cook E, Stevenson I. Features of "near-death experience" in relation to whether or not patients were near to death. Lancet 1990; 336:1.175-7.

19. Pepitone P, Arreola R. Death anxiety: comparison of psychiatrists, psycologists, suicidologists, and funeral directors. Psycol Rep 1981; 49: 979-82.

20. Keller J W, Sherry D, Piotrowski C. Perspectives on death: a developmental study. J Psychol 1984; 116: 137-42.

21. Loneto R, Templer, D. Death anxiety. Washington DC, Hemisphere Publishing, 1986. 